\title{
Prevalence of Symptoms of Post-Traumatic Stress, Depression and Anxiety Among Abused and Neglected Adolescents in Charitable Children's Institutions in Nairobi
}

\author{
Stella Kemuma Nyagwencha ${ }^{1, *}$, Alice Munene ${ }^{1}$, Naomi James ${ }^{1}$, Ricarda Mewes ${ }^{2}$, Antonia Barke $^{3}$ \\ ${ }^{1}$ Department of Psychology and Counseling, Daystar University, Nairobi, Kenya \\ ${ }^{2}$ Department of Psychology, University of Vienna, Vienna, Germany \\ ${ }^{3}$ Department of Psychology, Philipps University, Marburg, Germany
}

Email address:

stenyagwencha@yahoo.com(S. K. Nyagwencha),snyagwencha@daystar.ac.ke(S. K. Nyagwencha), amunene@daystar.ac.ke(A.Munene), naomijimmy@gmail.com(N.James), ricarda.nater-mewes@univie.ac.at (R. Mewes), abarke@gwdg.de(A. Barke)

*Corresponding author

To cite this article:

Stella Kemuma Nyagwencha, Alice Munene, Naomi James, Ricarda Mewes, Antonia Barke. Prevalence of Symptoms of Post-Traumatic Stress, Depression and Anxiety Among Abused and Neglected Adolescents in Charitable Children's Institutions in Nairobi. American Journal of Applied Psychology. Vol. 7, No. 2, 2018, pp. 37-43. doi: 10.11648/j.ajap.20180702.12

Received: May 17, 2018; Accepted: June 4, 2018; Published: June 18, 2018

\begin{abstract}
Children living in institutions experience separation from their birth parents and other caregivers. Further, they also suffer from the effects of abuse and neglect which led to their institutionalization as well as effects of institutional care despite the fact that their physical needs like food, clothing and shelter are adequately met. The purpose of this study was to establish the prevalence of symptoms of anxiety disorder, depression and post-traumatic stress disorder (PTSD) among adolescents with a history of abuse and neglect living in charitable children's institutions (CCIs) in Nairobi County, Kenya. Three purposely selected CCIs in Nairobi, Kenya, housing 341 adolescents aged between 13-18 years were studied. Of these, 232 adolescents provided informed consent or assent depending on age, reported sociodemographic data and answered questions about experiences of abuse and neglect. They also completed the Harvard Trauma Questionnaire (HTQ), Beck's Anxiety Inventory (BAI) and Beck's Depression Inventory II (BDI-II). Of the 232 respondents, 63.2\% had experienced abuse and neglect. Analyses of mental health symptoms indicated that symptoms of anxiety had the highest point prevalence of $84.1 \%$, followed by those of depression at $50.4 \%$ and PTSD at $21.6 \%$. Due to the abuse experienced, adolescents living in CCIs represent a vulnerable group in terms of mental health and psychological support adapted to the needs of this group should be provided.
\end{abstract}

Keywords: Anxiety, Depression, PTSD, Adolescents, Abuse, Charitable Children's Institutions, Kenya

\section{Introduction}

With the United Nations Convention on the Rights of the Child (UNCRC) formulated on $20^{\text {th }}$ November 1989 and ratified by 196 countries worldwide, among them Kenya, the legal status of children and adolescents changed [1]. In all countries of the treaty, children now have a right to fulfillment of their developmental needs. Although child abuse and neglect are incompatible with these rights, they continue to be a global problem [2] with negative effects on mental health up to years later [3].
Despite the fact that the Government of Kenya has put systems in place to protect children and adolescents from abuse and neglect, they are still at risk of abuse and neglect with some groups more so than others [4]. Risk factors for abuse and neglect of children and adolescents in Kenya, include, but are not limited to, geographical locations (such as Northern, North Eastern, Coastal areas), informal urban settlements, cultural practices such as female genital mutilation and early girl child marriage, socio-cultural factors that bring about gender inequality; low social and economic status, male sex for physical abuse and female sex for sexual abuse, violence and harmful practices, children lacking 
parental care and living in large families [4].

A national survey conducted in Kenya by Violence Against Children in 2010 found levels of violence (physical, sexual, emotional) to children and adolescents prior to 18 years to be $26 \%$ (females) and $32 \%$ (males) [5]. A study conducted in rural Kenya among 13-20 year old high school students found that $94.8 \%$ had been exposed to potentially traumatic events like rape $(9.8 \%)$, physical assault $(22.5 \%)$, sexual abuse (19.8\%), physical abuse (27.8\%), bullying $(32.2 \%)$ and childhood neglect (25.3\%) [6].

To protect children and adolescents from any form of maltreatment and make provision for their care and protection, the Kenyan governemnt passed a Children's Act in 2001 [7]. The act highlights the rights of children, parental responsibilities, administration of children's services and children's institutions mandated to care for them. Such institutions include rehabilitation schools, remand homes and charitable children's institutions (CCIs). Whereas it is the wish of the government of Kenya that each child is brought up in the care of loving and caring parents, in situations where family-based care, foster care, guardianship or adoption, is not possible, children often are sent to live in CCIs. CCIs are meant to provide temporary safe places for children at risk of harm. A CCI is an institution that has been established by a person, a corporate or a religious organization and has been granted approval by the Children's Department to manage a program for care, protection, rehabilitation or control of children [7].

Typical reasons why children go to live in CCIs are losing their caregiver or being abused or neglected by the caregiver without any extended family member stepping in to provide for the child's basic needs. At present, there are $830 \mathrm{CCIs}$ distributed across Kenya caring for more than 42,000 children [4]. The present study took place in Nairobi County which has the highest number of CCIs (approximately 400) in Kenya. While it is plausible to assume that children and adolescents who arrive at the CCI have had many adverse experiences, little is known about how many of them suffered abuse and how this affects their mental health.

In general, abuse and neglect negatively affect the development of children and adolescents by interfering with their physiological and psychological development. It often leads to suffering, reduced quality of life, development of internalizing and externalizing behaviors and a multitude of long-term mental and physical problems [8], [9]. Those effects have been found to appear and worsen in adolescence which is characterized by physical, cognitive, social and emotional changes [10]. With regard to mental disorders, studies found that people exposed to maltreatment, abuse and neglect often develop PTSD [11-14]. Moreover, anxiety disorders and depression are among the most common psychological disorders in children and adolescents and may result from abuse and neglect [14-17].

However, little is known about the prevalence of symptoms of PTSD, depression and anxiety disorders among abused and neglected adolescents living in CCIs in Kenya. A reason for this is that, geographically, most research centered on developed regions such as North America and Europe with scarce data being available for Africa, South America and Asia. Therefore, the purpose of this study was to establish the prevalence of symptoms of anxiety disorder, depression and PTSD among adolescents with a history of abuse and neglect living in CCIs in Nairobi County, Kenya. Further, contribute to the knowledge regarding abused or neglected adolescents in Kenya.

\section{Methods}

\subsection{Sample}

Research was conducted in three purposely selected CCIs due to the large number of adolescents they had. Children were allocated to the CCIs on the basis of children's court orders, referrals by religious organizations or individuals wherever there was a place. Further, the CCIs had similar characteristics as they were all in Nairobi County. The three CCIs were caring for 1149 children. Of these, 341 participants were in the eligible age range 13-18 years, with 232 providing informed consent or assent. The CCI administrator's provided informed consent on behalf of adolescents below age 18. Adolescents aged 18 years provided informed consent while those below 18 years provided assent. The participants' mean age was 15.3 years $(\mathrm{SD}=1.7)$ with 117 boys $(50.4 \%)$ and $115(49.6 \%)$ girls. The selected CCIs had schools, which the adolescents living in the homes attended. Through the head teachers, the school administration made an announcement of the intended research to the adolescents during a special assembly. Subsequently, a meeting was organized between the researchers and the adolescents. The researchers introduced themselves to the participants and explained the purpose of the study. Participants had the opportunity to ask questions about the research and signed informed consent and assent forms.

\subsection{Procedure and Methods}

Assessment was conducted in groups of 15-20 participants. The questionnaires were distributed in each group, then the researcher together with trained assistants read aloud each question and gave the participants time to answer it before moving on to the next question. This procedure was adopted to improve the understanding of the questions and guide the participants through the process in an ordered manner to reduce missing values. It also gave participants an opportunity to ask questions if they had difficulty understanding any particular item.

\subsubsection{Socio-demographic Information}

Information on socio-demographic variables was collected, asking for sex, age, when the adolescents came to live in the respective institution and what class they attended. The participants were also asked the reason why they came to live in the CCI. With regard to their families of origin, the questionnaire asked whether they knew their parents and, if 
so, whether their parents were living together and if the parents had ever received any psychiatric treatment. In addition, the adolescents were asked about the love and care they felt to have received from their mother/ father or other caregiver. Finally, they were asked whether they had experienced any kind of abuse (physical, sexual or emotional) or neglect in the past.

\subsubsection{PTSD}

Participants were administered the Harvard Trauma Questionaire (HTQ) to measure PTSD symptoms [18]. HTQ is a well-established instrument for the assessment of stresssymptoms after trauma $[30,31]$. The participants had to rate whether they experienced each of 16 symptoms in the last week from 1 (not at all) to 4 (extremely) with higher scores indicating a higher degree of symptoms of PTSD. The cut off for the presence of PTSD symptoms was set at a mean score greater than $>2.5$ [18]. The HTQ was successfully used in a prior study in Kenya with an internal consistency of Cronbach's $\alpha=.75$ [6]. The reliability of HTQ in the present study was Cronbach's $\alpha=.83$.

\subsubsection{Depression}

Symptoms of depression were measured using Beck's Depression Inventory-II (BDI-II) [21]. BDI-II consists of 21 items relating to symptoms of depression and feelings of hopelessness. Each symptom is rated with individual answers scoring from 0 to 3 , with higher scores indicating a higher degree of depressive symptoms. Cut off point for the presence of symptoms of depression was a score of 10 and above [22].

BDI's reliability yielded a Cronbach's alpha of .92 for an outpatient population ( $\mathrm{n}=500$; aged $13-80$ years) (Beck et al., 1996). BDI was successfully used in Kenya before [14], [20], [23]. Since item 21 (loss of sexual interest) may not be appropriate for a sample aged 13-18 years, the item was removed and - for the calculation of the sum score - replaced by the mean value of the person in the remaining items. The internal consistency of BDI-II in the present study was Cronbach's $\alpha=.89$.

\subsubsection{Anxiety}

Symptoms of anxiety were measured using Beck's Anxiety Inventory (BAI) [24]. BAI consists of 21 symptoms of anxiety and participants had to indicate how much they had been bothered by these symptoms in the last month from 0 (not at all) to 3 (severely - it bothered me a lot). Cut off point for presence of anxiety symptoms was a score of 8 and above [24].

BAI was validated against the Diagnostic and Statistical Manual of Mental Disorders (DSM-5) and successfully used in Kenya before [25]. In similar studies in Western countries, BAI demonstrated an internal consistency of Cronbach's $\alpha$ $=.92$ with a 1 week test-retest reliability of $\mathrm{BAI}=0.75$. In the present study, its internal consistency was Cronbach's $\alpha=.89$.

\subsubsection{Data Analysis}

It was calculated how many adolescents had suffered any kind of abuse or neglect by computing the frequency of the disjunction of sexual abuse, physical abuse, emotional abuse and neglect (termed any kind of abuse) and the number of adolescents who had not suffered any abuse (no abuse). This study did not establish whether the abuse happened prior to the adolescents coming to the CCI of after. The study just established that the participants had experienced abuse and neglect in their lifetime. We investigated group differences between adolescents who had suffered any kind of abuse and those without abuse regarding age, time living in the CCI and symptoms of anxiety, depression and post-traumatic stress by calculating independent $t$ tests. If Levene's test for variance homogeneity indicated unequal variances, the results of the Welch test are reported and the degrees of freedom adjusted accordingly. As measure of effect size, Cohen's $d$ is reported. Differences regarding sex and other non-parametric sociodemographic data were tested with the $\mathrm{Chi}^{2}$ test.

\section{Results}

A total of 232 adolescents aged 13-18 years participated in the study. The adolescents had been at the CCI for $42.7 \pm$ 47.3 months (range: 1 to 193 months). Most knew their parents $(\mathrm{n}=215 ; 92.7 \%$; see Table 1$)$. Fourteen percent of adolescents received medication for somatic illnesses, mostly chest complaints; none of them was treated for psychiatric disorders. Of the participants, $63.2 \%$ had experienced at least one type of abuse or neglect. According to the questionnaire and cut-off used (see methods section), the prevalence for a probable anxiety disorder was $84.1 \%$, depression $50.4 \%$ and PTSD $21.6 \%$. The adolescents who had experienced any kind of abuse did not differ from those who had not in sex or age, but they had been longer residents at the children's home and showed a higher degree of symptoms of PTSD, anxiety and depression. (See Table 2).

Table 1. Socio-demographic characteristics for the total sample and the group with and without abuse.

\begin{tabular}{|c|c|c|c|c|c|}
\hline \multirow{2}{*}{ Variables } & Whole sample $(n=232)$ & Any abuse $(n=146)$ & No abuse $(n=85) *$ & \multirow{2}{*}{$\mathrm{Chi}^{2}$} & \multirow{2}{*}{$p$} \\
\hline & f $(\%)$ & f $(\%)$ & f $(\%)$ & & \\
\hline \multicolumn{6}{|l|}{ Sex } \\
\hline Male & $117(50.4 \%)$ & $72(50.7 \%)$ & $37(49.3 \%)$ & \multirow{3}{*}{0.037} & \multirow{3}{*}{.85} \\
\hline Female & $115(49.6 \%)$ & $70(49.3 \%)$ & $38(50.7 \%)$ & & \\
\hline Medication & & & & & \\
\hline Yes & $32(13.9 \%)$ & $16(11.3 \%)$ & $14(18.7 \%)$ & \multirow{2}{*}{2.193} & \multirow{2}{*}{.14} \\
\hline No & $199(86.1 \%)$ & $125(88.7 \%)$ & $61(81.3 \%)$ & & \\
\hline Yes & $215(93.5 \%)$ & $131(92.9 \%)$ & $70(94.6 \%)$ & \multirow{2}{*}{0.227} & \multirow{2}{*}{.63} \\
\hline No & $15(6.5 \%)$ & $10(7.1 \%)$ & $4(5.4 \%)$ & & \\
\hline
\end{tabular}




\begin{tabular}{|c|c|c|c|c|c|}
\hline \multirow{2}{*}{ Variables } & Whole sample $(\mathrm{n}=\mathbf{2 3 2})$ & Any abuse $(n=146)$ & No abuse $(\mathrm{n}=85)^{*}$ & \multirow{2}{*}{$\mathrm{Chi}^{2}$} & \multirow[b]{2}{*}{$p$} \\
\hline & $f(\%)$ & f $(\%)$ & f (\%) & & \\
\hline \multicolumn{6}{|c|}{ Parents treated by a psychiatrist } \\
\hline Yes & $48(25.1 \%)$ & $28(23.7 \%)$ & $15(24.2 \%)$ & 0.005 & .95 \\
\hline No & $143(74.9 \%)$ & $90(76.3 \%)$ & $75.8 \%)$ & 0.005 & 90 \\
\hline
\end{tabular}

* One participant failed to answer the question whether he had experienced any abuse

Table 2 Comparison of age, symptoms of anxiety, depression and PTSD levels of children who had experienced abuse and those who had not experienced any abuse by means of independent $t$ tests.

\begin{tabular}{|c|c|c|c|c|c|c|c|c|}
\hline & \multicolumn{2}{|c|}{ No abuse $(n=75)$} & \multicolumn{2}{|c|}{ Any Abuse (n =142) } & \multirow[b]{2}{*}{$t$} & \multirow{2}{*}{$d f$} & \multirow{2}{*}{$p$} & \multirow{2}{*}{ Cohen's $d$} \\
\hline & Mean & SD & Mean & SD & & & & \\
\hline $\operatorname{Age}^{a}$ & 15.6 & 1.5 & 15.2 & 1.8 & 1.765 & 168.941 & .079 & 0.24 \\
\hline Residency & 31.0 & 45.3 & 49.2 & 47.3 & -2.573 & 191 & .011 & 0.39 \\
\hline Anxiety (BAI) & 16.7 & 12.1 & 23.0 & 12.7 & -3.556 & 215 & $<.001$ & 0.51 \\
\hline Depression (BDI-II) ${ }^{\mathrm{a}}$ & 10.2 & 9.6 & 13.1 & 11.0 & -2.051 & 169.524 & .042 & 0.28 \\
\hline PTSD (HTQ) & 30.6 & 9.4 & 33.9 & 9.5 & -2.463 & 215 & .015 & 0.35 \\
\hline
\end{tabular}

Notes: BAI: Beck’s Anxiety Inventory, BDI-II: Beck Depression Inventory II, HTQ: Harvard Trauma Questionnaire;

${ }^{a}$ Levene's test indicated inequality of variance, therefore, the Welch test is reported and the degrees of freedom were adjusted accordingly.

\section{Discussion}

Our main findings showed that more than $60 \%$ of adolescents living in CCIs in Nairobi had experienced abuse and neglect and many suffered from a high level of mental symptoms. Moreover, we found that the adolescents who had experienced abuse and neglect had been resident at the homes for longer and exhibited higher levels of symptoms.

Comparing the results with other studies has to take into account differences in definitions of abuse, measurements and samples. Many previous studies focused on different types of abuse and or neglect which may have been targeted at the children or witnessed by the children. However, our study looked at 4 types of abuses directed at the adolescents and its impact on their mental health. The present study found that $63.2 \%$ of participants had experienced at least one type of abuse and neglect. This dovetails with a study conducted in Western Kenya, which investigated maltreatment experiences of children prior to admission to a $\mathrm{CCI}$ and found that $66 \%$ had experienced at least one form of maltreatment [26].

The forms of maltreatment Morantz and colleagues identified include neglect, abandonment, physical and sexual abuse among others. This is an indication that the numbers found may be an accurate reflection of the situation with regard to children living in Kenyan CCIs. Our study did not establish whether the abuse and neglect experienced by adolescents living in CCIs happened prior to admission or after admission. However, the most common reason for admission to a CCI is abuse, thus it seems likely that in most cases the abuse and neglect had taken place prior to admission. Expectedly, our findings were higher than findings of adolescent samples in general Kenyan adolescent populations, who lived in their homesteads [5], [27], [28].

Significant associations were found between the length of time an adolescent stayed in the CCI and exposure to abuse and neglect similar to findings of a study conducted in Kenya where the age of admission of a child to a CCI was associated with previous maltreatment [26]. Reasons could be that these children had been rescued at an early age due to the severity of abuse or maltreatment they had been exposed to. In our study a possible explanation could also be that children who had experienced abuse were less likely to be discharged from the CCI because the situations that led to the abuse persisted. However, more research is needed to find out the trajectories of those children and adolescents and shed light on this association.

Our study agrees with previous research showing that abuse and neglect are associated with mental illness [29], [30]. In the present study, adolescents with a history of abuse and neglect reported higher symptoms of PTSD, depression and anxiety compared to those who had not experienced any abuse and neglect. However, the prevalence of probable PTSD was higher $(21.6 \%)$ in our sample than in a similar study conducted in Western Kenya (11.5\%) among orphans or separated children living in 19 CCIs. This study used the Child PTSD checklist where a child was considered to have PTSD if they experienced 6 out of the 17 PTSD symptoms (1 re-experiencing symptom, 3 symptoms of avoidance and 2 for hyper arousal symptoms) on DSM-IV [31]. Our study used a cut off of $>2.5$ in HTQ scores which means that a child must have experienced more than half of the symptoms (8 items out of 16).

Similarly, a study conducted in the general population among households in Maseno, Kenya, found a lower prevalence of PTSD at $10.6 \%$ when a participant scored six or more in the Trauma Screening Questionnaire [32]. However, in that study, PTSD symptoms were only assessed if the traumatic event had happened after the age of 16 years, while our study included lifetime events. It is important to note that the prevalence of PTSD in Maseno and Western Kenya, which are both rural areas in Kenya, are close together compared to findings of Nairobi which is an urban area which could be a risk factor for abuse and neglect itself [4].

A longitudinal study conducted in Kenya among 191 children age 7-17 years who had experienced sexual abuse found that at baseline the prevalence of full PTSD was $95.3 \%$ 
[33]. This finding could have been higher than this study because the research was done in the biggest referral hospital in Kenya.

Similarly, other studies conducted in rural Kenya among secondary school students found higher prevalence of PTSD at $34.5 \%$ conducted in Central and Northern Kenya (also using the HTQ [6]. In another study among students in 49 public secondary schools located in urban and rural areas, $50.5 \%$ met full criteria (criteria A-E were met in DSM-IV-R for PTSD) and 34.8\% met partial criteria (1 symptom was checked in each DSM-IV symptom criterion) using the Child PTSD checklist [13]. The studies explained the wide variations as being caused by socio-demographic factors and type of traumatic event experienced.

However, one would expect that adolescents of the general population surveyed in secondary schools would show lower rates of symptoms of PTSD compared to adolescents living in CCIs. This has been attributed to bullying, which was very common in Kenyan schools [16]. One could hypothesize whether this may explain the high prevalence of PTSD in the high school sample. However, this would be highly speculative. Clearly, more research is needed to find out which factors contributed to results suggesting that adolescents in secondary schools in Kenya have such high rates of PTSD. Most studies concerned with trauma, abuse or neglect have concentrated on PTSD. This study went further to establish the prevalence of probable depression and anxiety disorders among adolescents who had a history of abuse and neglect.

The prevalence of probable anxiety disorder in the present study $(84.1 \%)$ was very high compared to other studies conducted in Kenya (12.9\%) using multidimensional anxiety scale for children (MASC) and 49.3\% using Ndetei-OthienoKathuku scale (NOK) [16]. Other than differences in measures used, some of the reasons why the anxiety score for children living in CCIs would be higher than adolescents in the general population could be because adolescents living in CCIs are placed there as temporary places of care and protection.

The placement is reviewed every 3 years within which they can be moved to another CCI, left in the same CCI or placed in foster care. In addition, the residents are expected to exit the CCI at the age of 18 , which may be a source of anxiety to those adolescent who may not have a safe place to go.

The prevalence of probable depression disorder in this study $(50.4 \%)$ was higher than $43.7 \%$ prevalence found among 775 randomly sampled students in Nairobi, Kenya (Ndetei et al., 2008) and 26.4\% prevalence found among 1276 adolescents in public secondary schools in Nairobi, Kenya using Child Depression Inventory (CDI) [22]. The prevalence of depressive symptoms among adolescents living in CCIs was higher than that of adolescents attending secondary schools in Nairobi county because adolescents living in CCIs have experienced severe abuse and neglect which has led to them being removed from their homes compared to adolescents still living in their homesteads.
However, a study conducted in Gaza among 81 orphaned children living in an institution found a higher prevalence of depression at $67.9 \%$ than this study [34]. This is because orphaned children living in an institution are considered vulnerable children as they struggle with issues of loss and grief as well as being institutionalized..

\section{Conclusion}

Our findings indicate that adolescents living in CCIs experience abuse and neglect which is linked to higher symptoms of PTSD, depression and anxiety. More research is needed to suggest effective ways to intervene and prevent adolescents experiencing abuse, neglect or any form of maltreatment. Future studies should establish when the abuse or neglect most often occurs to inform policy makers on the best ways to timely protect adolescents at risk. Given the high levels of symptoms encountered, it may also be important that children living in CCIs have access to counseling that helps them to deal with traumatic experiences

\section{Ethics}

The study was approved by Daystar University Ethics and Review Board, Daystar University Department of Human and Social Sciences, National Council for Science and Technology in Kenya (NACOSTI) and the directors of the three CCI's. Adolescents aged 18 years provided informed consent while those below 18 years provided assent.

\section{Limitations}

The assessment of lifetime maltreatment with dichotomous items as well as the restricted generalizability constitute important shortcomings of the study.

\section{Conflict of Interest}

The authors declare that they have no conflict of interest

\section{Acknowledgements}

German Academic Exchange Program (DAAD) through In country/In region scholarship ref. no. 91601924- Research Assistants Jeremiah Kipkosgei, Rahab Karanja, Gertrude Nyiramana.

\section{References}

[1] UN General Assembly, "DECLARATION OF THE RIGHTS OF THE CHILD," in Declaration of the Rights of the Child.

[2] M. Stoltenborgh, M. J. Bakermans-Kranenburg, L. R. A. Alink, and M. H. van IJzendoorn, "The Prevalence of Child Maltreatment across the Globe: Review of a Series of MetaAnalyses," Child Abus. Rev., vol. 24, no. 1, pp. 37-50, Jan. 2015. 
[3] A. Lazenbatt, "The impact of abuse and neglect on the health and mental health of children and young people," ... Prev. Cruel. to Child. Available online ..., no. February, pp. 1-25, 2010.

[4] Government of Kenya. UNICEF. Global Affairs Canada, "Taking child protection to the next level in Kenya," 2015.

[5] UNICEF, "Violence Against Children in Kenya: Findings from 2010 National Survey," 2012.

[6] S. H. Karsberg and A. Elklit, "Victimization and PTSD in A Rural Kenyan Youth Sample.," Clin. Pract. Epidemiol. Ment. Health, vol. 8, pp. 91-101, 2012.

[7] 2001 (Kenya) The Children Act, "Kenya: Children's Act 8 of 2001," vol. No. 8 of 2, 2001.

[8] L. L. Carpenter, T. T. Shattuck, A. R. Tyrka, T. D. Geracioti, and L. H. Price, "Effect of childhood physical abuse on cortisol stress response.," Psychopharmacology (Berl)., vol. 214, no. 1, pp. 367-75, Mar. 2011.

[9] J.-Y. Feng, Y.-T. Chang, H.-Y. Chang, S. Fetzer, and J.-D. Wang, "Prevalence of different forms of child maltreatment among Taiwanese adolescents: A population-based study," Child Abuse Negl., vol. 42, pp. 10-19, 2015.

[10] A. Lamont and L. Bromfield, "Effects of child abuse and neglect for children and adolescents," Natl. Child Prot. Clear. House, vol. 1, p. 7, 2010.

[11] C. P. McLean, S. H. Morris, P. Conklin, N. Jayawickreme, and E. B. Foa, "Trauma Characteristics and Posttraumatic Stress Disorder among Adolescent Survivors of Childhood Sexual Abuse," J. Fam. Violence, vol. 29, no. 5, 2014.

[12] S. Pokhariyal, G. P., Rono, R., Munywoki, "full-text," Traumatology (Tallahass. Fla)., vol. 19, no. 2, pp. 107-117, 2012.

[13] D. M. Ndetei, F. A. Ongecha-Owuor, L. Khasakhala, V. Mutiso, G. Odhiambo, and D. A. Kokonya, "Traumatic experiences of Kenyan secondary school students," J. Child Adolesc. Ment. Heal., vol. 19, no. 2, pp. 147-155, Oct. 2007.

[14] L. I. Khasakhala, D. M. Ndetei, V. Mutiso, A. W. Mbwayo, and M. Mathai, "The prevalence of depressive symptoms among adolescents in Nairobi public secondary schools: association with perceived maladaptive parental behaviour.," Afr. J. Psychiatry, vol. 15, no. 2, pp. 106-13, Mar. 2012.

[15] F. Atieno Aboge, A. Obondo, D. Kathuku, and D. Kibuule, "The Prevalence of Depressive Symptoms among Sensory and Physically Challenged Persons Living with HIV/AIDS Attending Clinics in Nyanza Province, Kenya," J. Depress. Anxiety, vol. 4, no. 2, 2015.

[16] D. Ndetei et al., "The prevalence of anxiety and depression symptoms and syndromes in Kenyan children and adolescents," J. Child Adolesc. Ment. Heal., vol. 20, no. 1, pp. 33-51, Aug. 2008.

[17] A. Schimmenti and A. Bifulco, "Linking lack of care in childhood to anxiety disorders in emerging adulthood: the role of attachment styles," Child Adolesc. Ment. Health, vol. 20, no. 1, pp. 41-48, Feb. 2015.

[18] R. F. Mollica, Y. Caspi-Yavin, P. Bollini, T. Truong, S. Tor, and J. Lavelle, "The Harvard Trauma Questionnaire. Validating a cross-cultural instrument for measuring torture, trauma, and posttraumatic stress disorder in Indochinese refugees.," J. Nerv. Ment. Dis., vol. 180, no. 2, pp. 111-6, Feb. 1992.

[19] M. R. Shoeb, Marwa., Weinstein, Harvey., "The Harvard Trauma Questionnaire: Adapting a Cross-Cultural Instrument measuring Torture, Trauma and Posttraumatic Stress disorder in Iraqi Refugees," Int. J. Soc. Psychiatry, vol. 53, no. 5, p. 447, 2007.

[20] H. P. Söndergaard, S. Ekblad, and T. Theorell, "Screening for post-traumatic stress disorder among refugees in Stockholm," Nord. J. Psychiatry, vol. 57, no. 3, pp. 185-189, Jan. 2003.

[21] A. T. Beck, R. A. Steer, and G. Brown, "BDI-II psychometric properties," NCTSN, 1996. [Online]. Available: http://nctsn.org/sites/default/files/assets/pdfs/measures/BDIII.pdf. [Accessed: 31-Jul-2017].

[22] A. T. Beck, C. H. Ward, M. Mendelson, J. Mock, and J. Erbaugh, "An inventory for measuring depression.," Arch. Gen. Psychiatry, vol. 4, pp. 561-71, Jun. 1961.

[23] D. M. Ndetei, F. A. Ongecha-Owuor, L. Khasakhala, V. Mutiso, G. Odhiambo, and D. A. Kokonya, "Traumatic experiences of Kenyan secondary school students," J. Child Adolesc. Ment. Health, vol. 19, no. 2, pp. 147-155, 2007.

[24] A. T. Beck, N. Epstein, G. Brown, and R. A. Steer, “An inventory for measuring clinical anxiety: Psychometric properties.," J. Consult. Clin. Psychol., vol. 56, no. 6, pp. 893-897, 1988.

[25] I. M. Nyaga, "Prevalence of PTSD, depression and anxiety among female survivors of rape following Post Election violence 2007 December Nairobi-Kenya," unpublished, 2010 .

[26] G. Morantz, D. C. Cole, S. Ayaya, D. Ayuku, and P. Braitstein, "Maltreatment experiences and associated factors prior to admission to residential care: A sample of institutionalized children and youth in western Kenya," Child Abuse Negl., vol. 37, no. 10, pp. 778-787, Oct. 2013.

[27] M. R. Infurna, C. Reichl, P. Parzer, A. Schimmenti, A. Bifulco, and M. Kaess, "Associations between depression and specific childhood experiences of abuse and neglect: A metaanalysis," J. Affect. Disord., vol. 190, pp. 47-55, 2015.

[28] T. N. Brockie, G. Dana-Sacco, G. R. Wallen, H. C. Wilcox, and J. C. Campbell, "The Relationship of Adverse Childhood Experiences to PTSD, Depression, Poly-Drug Use and Suicide Attempt in Reservation-Based Native American Adolescents and Young Adults," Am. J. Community Psychol., vol. 55, no. 3-4, pp. 411-421, Jun. 2015.

[29] T. O. Afifi, H. L. MacMillan, M. Boyle, T. Taillieu, K. Cheung, and J. Sareen, "Child abuse and mental disorders in Canada.," Can. Med. Assoc. J., vol. 186, no. 9, pp. e324-32, Jun. 2014.

[30] A. M. Naughton, L. E. Cowley, V. Tempest, S. A. Maguire, M. K. Mann, and A. M. Kemp, "Ask Me! self-reported features of adolescents experiencing neglect or emotional maltreatment: a rapid systematic review," Child. Care. Health Dev., vol. 43, no. 3, pp. 348-360, May 2017.

[31] L. Atwoli et al., "Impact of domestic care environment on trauma and posttraumatic stress disorder among orphans in western Kenya.," PLoS One, vol. 9, no. 3, p. e89937, 2014. 
[32] R. Jenkins et al., "Probable Post Traumatic Stress Disorder in Kenya and Its Associated Risk Factors: A Cross-Sectional Household Survey.," Int. J. Environ. Res. Public Health, vol. 12, no. 10, pp. 13494-509, Oct. 2015.

[33] T. Mutavi, M. Mathai, and A. Obondo, "Post-Traumatic Stress Disorder (PTSD) in Sexually Abused Children and
Educational Status in Kenya: A Longitudinal Study," J. Child Adolesc. Behav., vol. 5, no. 5, pp. 1-8, Sep. 2017.

[34] M. A. Rashid, A., Aziz, A., Thabet, "Prevalence of PTSD, Depression, and Anxiety Among Orphaned Children in the Gaza Strip - Semantic Scholar," ECRONICON OPEN ACCESS, vol. 5, no. 6, pp. 159-169, 2017. 